\title{
Transmission electron microscopy characterization of laser welding cast Ni-based superalloy K418 turbo disk and alloy steel 42CrMo shaft
}

\author{
Xiu-Bo Liu ${ }^{\mathrm{a}, \mathrm{b}}$, Ming Pang ${ }^{\mathrm{a}}$, Jian Guo ${ }^{\mathrm{b}}$, Gang Yu ${ }^{\mathrm{a}, *}$ \\ a State Key Laboratory of Nonlinear Mechanics, Institute of Mechanics, Chinese Academy of Sciences, 15 Beisihuanxi Road, Beijing 100080, PR China \\ ${ }^{\mathrm{b}}$ School of Materials \& Chemical Engineering, \\ Zhongyuan Institute of Technology, 41 Zhongyuan Western Road, Zhengzhou 450007, Henan Province, PR China
}

Received 13 June 2007; received in revised form 17 July 2007; accepted 21 July 2007

Available online 26 July 2007

\begin{abstract}
Microstructure characterization is important for controlling the quality of laser welding. In the present work, a detailed microstructure characterization by transmission electron microscopy was carried out on the laser welding cast Ni-based superalloy K418 turbo disk and alloy steel $42 \mathrm{CrMo}$ shaft and an unambiguous identification of phases in the weldment was accomplished. It was found that there are $\gamma$-FeCrNiC austenite solid solution dendrites as the matrix, (Nb, Ti) $\mathrm{C}$ type $\mathrm{MC}$ carbides, fine and dispersed $\mathrm{Ni}_{3} \mathrm{Al} \gamma^{\prime}$ phase as well as Laves particles in the interdendritic region of the seam zone. A brief discussion was given for their existence based on both kinetic and thermodynamic principles.
\end{abstract}

(C) 2007 Elsevier B.V. All rights reserved.

Keywords: Laser welding; Microstructure characterization; Transmission electron microscopy

\section{Introduction}

In China, turbo-compressor rotor, a core component of turbo-compressor, is usually manufactured by welding the Chinese cast Ni-based super-alloy K418 turbo disk to the quench-tempered Chinese 42CrMo alloy steel shaft. Yet, the thermal-physical and high-temperature mechanical properties of the above two materials are so different and the Ni-based super-alloy possesses great susceptibility to cracking in the heat affected zone (HAZ) during welding. Moreover, the carbon equivalent of the medium carbon steel $42 \mathrm{CrMo}$ is about $0.834 \%$, which means it possesses strong quenching harden tendency during welding, their welding process belongs to the typically dissimilar materials welding and is usually considered to be a great challenge. At present, the welding methods of these two materials are either electronic-beam welding or friction welding. However, the electronic-beam welding process needs vacuum chamber and produces harmful X-rays. On the other hand, building a large vacuum chamber to contain very huge component

\footnotetext{
* Corresponding author. Tel.: +8610 8254 4250; fax: +86 1082544250 .

E-mail addresses: liubobo0828@yahoo.com.cn (X.-B. Liu), gyu@imech.ac.cn (G. Yu).
}

to carry on the electronic beam welding is not practicable. As for the friction welding, low stress destruction often occurred and welding defects are usually observed near the fusion zone, resulting in lower production efficiency. For a long time, failures of such joints have plagued Chinese turbo-compressor makers [1-4].

Laser welding is a high energy-density, low heat-input process with specific advantages over conventional fusion welding processes. These include high welding speed, narrow heataffected zone, low distortion, ease of automation, single-pass thick section capability and enhanced design flexibility. One of the many features of laser welding is the capability to weld without filler materials (autogenous welding) and it offers distinct advantages [5-9]. Laser welding has recently received growing attention due to its special features and potential. In terms of weldability for metallic materials, Nd:YAG laser has various advantages, such as a high energy absorption rate due to a low reflectivity, a high welding speed, and a low residual stress compared to $\mathrm{CO}_{2}$ laser. Therefore, the application of Nd:YAG laser to weld metallic materials is steadily being increased. It has been widely implemented in industrial applications, e.g. in the automotive industry $[10,11]$. But presently, laser power levels are still limited for the material thickness involved. Recently, we have successfully made the full penetration butt welding joints 
between K418 and 42CrMo flat plates with the same thickness of $3.5 \mathrm{~mm}$ by appropriate selection of processing parameters [12]. Although the microhardness of the laser-welded seam was lower than that of the base metal, the strength of the joint was equal to that of the base metal and the fracture mechanism showed fine ductility.

In our recent related studies [13,14], laser welding K418 turbo disk and 42CrMo shaft were conducted. Attempts to characterize the microstructure of the phases present in the seam zone were made on X-ray diffraction (XRD) analysis, scanning electron microscope (SEM) and energy-dispersive spectrometer (EDS). Results showed that the weld had non-equilibrium solidified microstructures consisting of $\gamma$-FeCrNiC austenite solid solution dendrites as the dominant and some fine and dispersed $\mathrm{Ni}_{3} \mathrm{Al}$ $\left(\gamma^{\prime}\right)$ phase and Laves particles as well as little amount of MC type short stick or particle-like carbides distributed in the interdendritic regions. However, there still exist three problems, the first is that it is usually hard to exactly identify and clearly marked the $\mathrm{Ni}_{3} \mathrm{Al}\left(\gamma^{\prime}\right)$ phase due to the relatively small amount and the superposed distribution with Laves phase and MC carbides although the XRD results indicate its existence. The second is Laves phase is heavily alloyed with multiple elements and its form is very complex, no present JCPDS cards could be found to identify the exact existence of it as mentioned in [13]. The third is that according to JCPDS standard data, interplanar spacing corresponding to diffraction peaks of possible phases in the fusion zone is close to each other, and the strong reflections of these phases are almost superimposed on one another. Nonequilibrium processes involved in the laser welding resulted in an extension of solubility and distortion of the lattices. Thus, transmission electron microscopy (TEM) is an ideal tool for microstructure and crystal structure characterization because it provides the image resolution and analytical tools needed to resolve these ambiguities. TEM have been applied successfully for studying the structure of a number of laser-processed materials [15-17]. In this paper, we present results on a structural study of laser welding Ni-based super-alloy K418 turbo disk and alloy steel 42CrMo shaft using conventional TEM.

\section{Experimental procedure}

K418 Ni-based casting superalloy turbo disk and the quench-tempered $42 \mathrm{CrMo}$ steel shaft, with their outer diameter of $38.5 \mathrm{~mm}$ and inner diameter of $27.5 \mathrm{~mm}$, i.e., thickness of $5.5 \mathrm{~mm}$, were selected as the welding components. Before welding, any oxide layers and contamination were removed from the surfaces of the components, especially the surfaces needed welding were cleaned with acetone, ethanol and then dried. The accuracy requirement for the platform is very high during laser-welding process, the horizontal and vertical accuracies were adjusted through the micrometer and the error range was within $0.04 \mathrm{~mm}$. Flow of high purity argon gas was passed through the molten pool from both top and lateral sides to provide a protective environment for the sake of avoiding the reaction between the molten metals and ambient air. Further details on laser welding and sample preparation procedures can be found in our previous work [13].

In this study, thin foils were prepared by cutting slices $(0.15 \mathrm{~mm}$ thick) from the central typical region of the solidified fusion zone from the welded joint based on our previous OM and SEM observations [13], by electric discharging machine. The slices were first ground mechanically to less than $50 \mu \mathrm{m}$. Discs of $3 \mathrm{~mm}$ diameter were punched mechanically and then dimpled by means of a Gatan Model 656 Dimple Grinder. Then metallic thin foil specimens

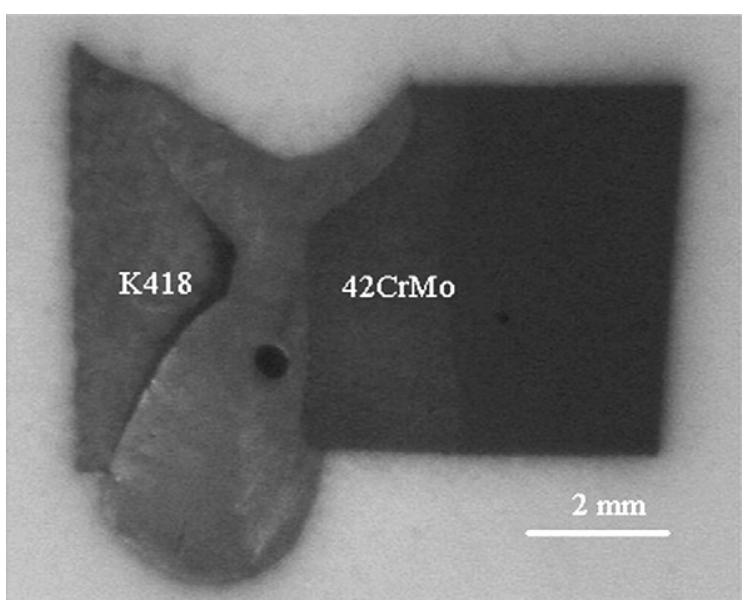

Fig. 1. Morphology of the laser weld between cast Ni-based superalloy K418 turbo disk and alloy steel 42CrMo shaft [13].

were prepared by ion bombardment technique and the structure was examined using the JEM-2100F Field Emission Transmission Electron Microscope (TEM, Japan).

\section{Results and discussion}

\subsection{Morphology of the weld}

The cross-section overview of the weld was shown in Fig. 1. It could be seen that no full penetration welding had been formed due to the relatively low rated laser output power and the thickness of the components. Shallow concave shape existed in the cap region and the remnant metal droplet left at the root region and inclined to the K418 alloy side, which possessed lower thermal conduction coefficient. Some pores were formed in the central region and inclined to the partially melted zone of 42CrMo, which had the higher melting point and strong thermal conduction capability. The optical and scanning electron microstructure revealed the existence of four phases: $\gamma$-FeCrNiC austenite solid solution dendrites as the matrix, ( $\mathrm{Nb}, \mathrm{Ti}) \mathrm{C}$ type MC carbides, fine and dispersed $\mathrm{Ni}_{3} \mathrm{Al}\left(\gamma^{\prime}\right)$ phase as well as Laves particles in the interdendritic regions.

\subsection{TEM observation}

TEM and SAED pattern analysis revealed the presence of matrix as the prominent phase in the welding fusion zone, as can be seen in Fig. 2(a) and (b). The corresponding EDS analysis results is shown in Table 1, which indicates that the matrix is highly enriched in $\mathrm{Ni}, \mathrm{Fe}$ and $\mathrm{Cr}$. Considering that the electron probe cannot detect the constitution of minor $\mathrm{C}$, so it is reasonable to deduce that this result is consistent with our previous XRD, OM and SEM-EDS analyses [13] that the matrix is $\gamma$-FeCrNiC austenite solid solution.

Fig. 3(a) shows the presence of MC type carbides particles in the welded seam and the SAED pattern (Fig. 3b) indicates the carbides possess a face-centered-cubic (fcc) crystal structure. The corresponding EDS analysis results (Table 1) corroborated the above analysis that the particles are $\mathrm{Nb}$, Ti enriched ( $\mathrm{Ti}$, 
Table 1

EDS analysis results of the laser welded seam zone (wt.\%)

\begin{tabular}{|c|c|c|c|c|c|c|c|c|c|}
\hline & \multicolumn{9}{|c|}{ Major elements } \\
\hline & $\mathrm{Ni}$ & $\mathrm{Fe}$ & $\mathrm{Cr}$ & Mo & $\mathrm{Al}$ & $\mathrm{Nb}$ & $\mathrm{Ti}$ & $\mathrm{Cu}$ & $\mathrm{O}$ \\
\hline Matrix & 45.12 & 35.49 & 10.56 & - & 2.20 & - & - & 6.63 & - \\
\hline $\mathrm{Ni}_{3} \mathrm{Al}$ & 40.02 & 26.21 & 8.60 & - & 12.59 & - & - & 2.57 & 10.01 \\
\hline Laves particles & 25.46 & 19.45 & 7.27 & 3.90 & 1.96 & 15.20 & 19.46 & 7.29 & - \\
\hline
\end{tabular}
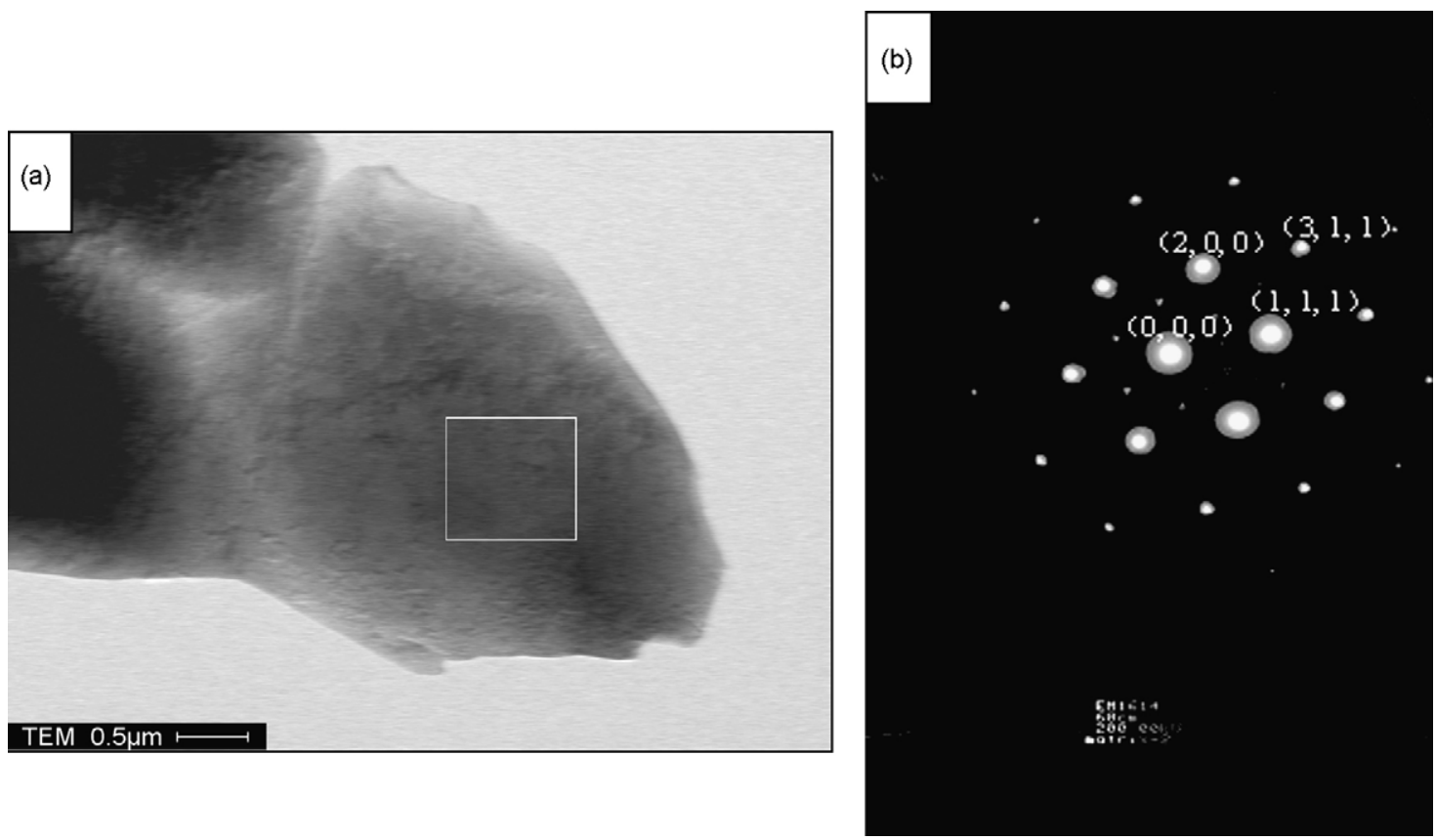

Fig. 2. $\gamma$-FeCrNiC austenite solid solution dendrites matrix in the welded seam: (a) bright field image, (b) SAED pattern in $\left[\begin{array}{lll}0 & 1 & \overline{1}\end{array}\right]$ zone axis.

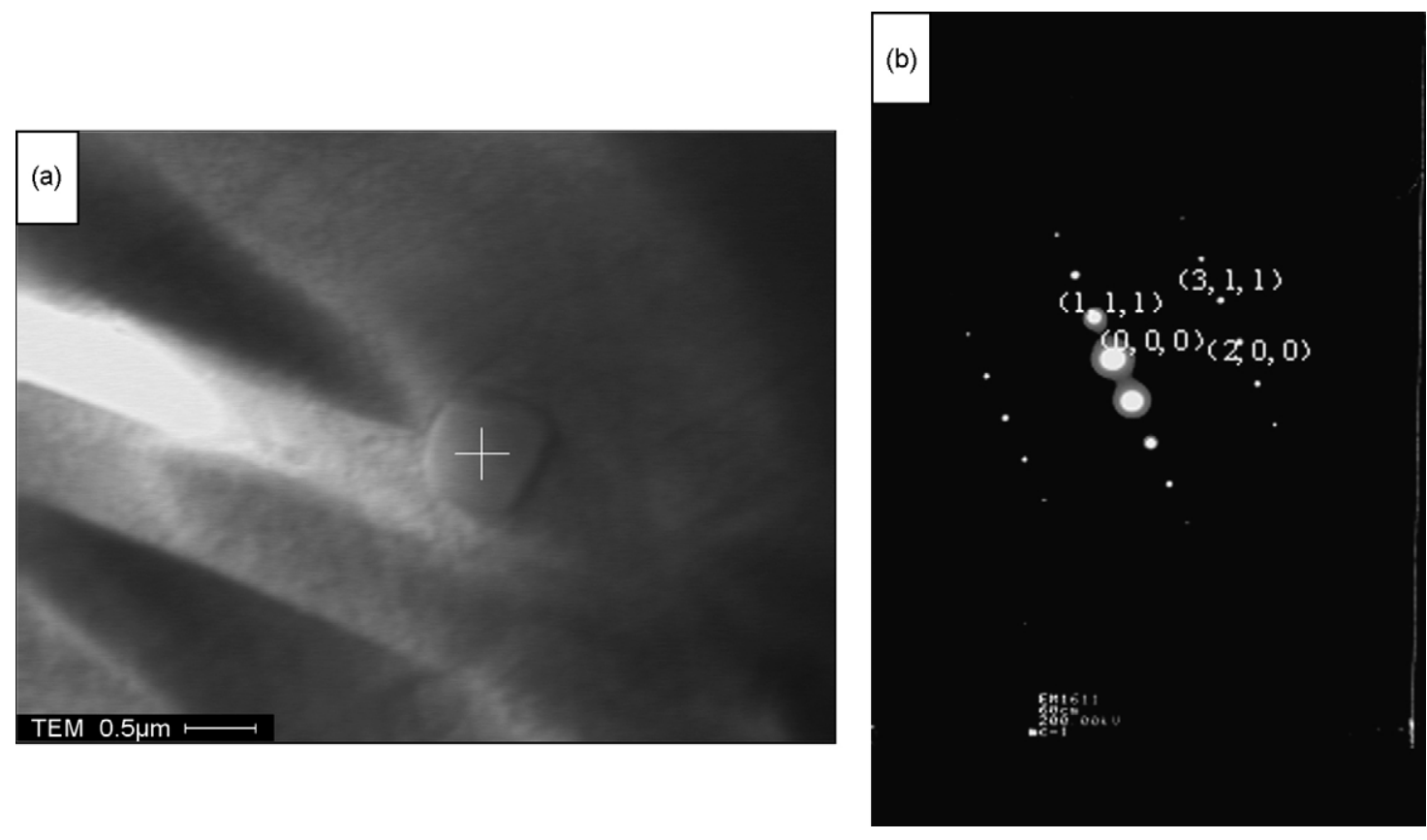

Fig. 3. MC type (Nb, Ti)C carbides in the welded seam: (a) bright field image, (b) SAED pattern in [0 $11 \overline{1}]$ zone axis. 


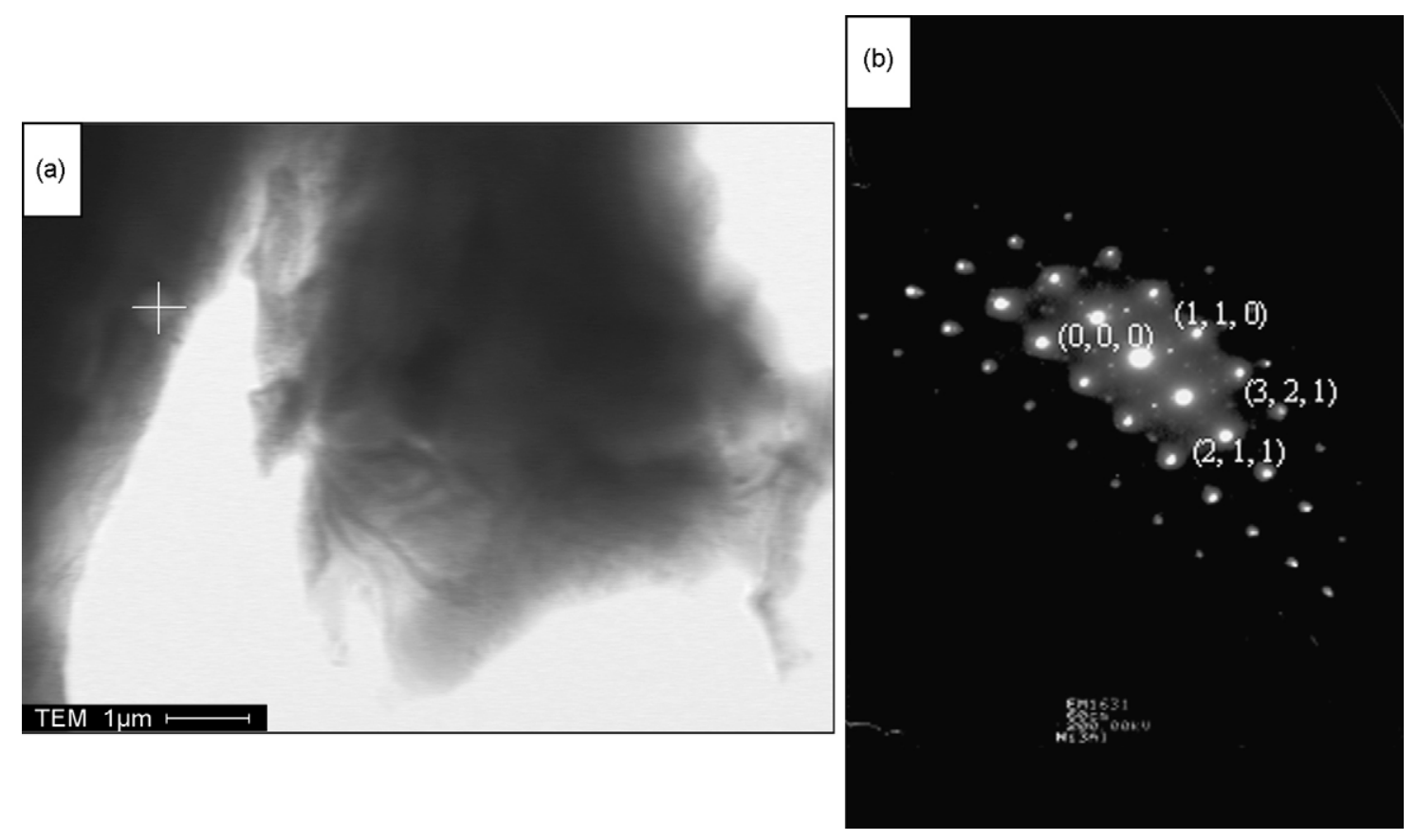

Fig. 4. $\mathrm{Ni}_{3} \mathrm{Al} \gamma^{\prime}$ phase in the welded seam: (a) bright field image, (b) SAED pattern in [1 1111$]$ zone axis.

$\mathrm{Nb}$ ) C carbides. Some $\mathrm{Cu}$ element was also detected because the TEM sample holder is $\mathrm{Cu}$ grid net.

Fig. 4(a) represents the dispersed $\mathrm{Ni}_{3} \mathrm{Al} \gamma^{\prime}$ phase, which is the main strengthening phase in most nickel-based superalloy, although its size was significantly refined (less than $1 \mu \mathrm{m}$ ) due to the laser beam welding induced non-equilibrium rapid solidification and its amount was lessened because of its partial dissolution, it can be clearly distinguished in SAED pattern and the corresponding EDS analyses, as can be seen in Fig. 4(b) and Table 1.

Fig. 5(a) shows the presence of the dispersed Laves particles, the EDS results show that the particles are enriched in $\mathrm{Nb}, \mathrm{Mo}$, Ti and lean in $\mathrm{Ni}, \mathrm{Cr}$ and $\mathrm{Fe}$ as compared to the solid solution dendrites matrix. Chemical composition of the particles enriched in $\mathrm{Nb}$ were identified as $(\mathrm{Fe}+\mathrm{Cr}+\mathrm{Ni}, 56.2 \%)$ and $(\mathrm{Nb}+\mathrm{Mo}+\mathrm{Ti}$, $38.5 \%)$, which is generally possess the form of $(\mathrm{Ni}, \mathrm{Cr}, \mathrm{Fe})_{2}(\mathrm{Nb}$, $\mathrm{Mo}, \mathrm{Ti}$ ) and has a $\mathrm{MgZn}_{2}$ type hexagonally closed packed (hcp) Laves crystal structure. This result is somewhat different with our previous work [12]. In that case, Laves particle possess the chemical composition of $(\mathrm{Fe}+\mathrm{Cr}+\mathrm{Ni}, 70 \%)$ and $(\mathrm{Nb}+\mathrm{Mo}+\mathrm{Ti}$, $28 \%$ ) under the investigation of SEM-EDS. There are mainly two reasons that could be explained as follows: The first one is that in our previous work, the plate is only $3.5 \mathrm{~mm}$ thick, so the welding velocity could be relatively fast to get a full penetration welding, thus the heavy alloy elements like $\mathrm{Nb}$, Mo and $\mathrm{Ti}$ do not have enough time to diffuse to segregate. As segregation is a prerequisite for the initiation of Laves phase, and segregation is a time-dependent phenomenon and hence, is strongly affected by the welding cooling rate, as influenced by welding velocity and the resultant welding cooling rate, so the amount of Laves phase and the content of $(\mathrm{Nb}+\mathrm{Mo}+\mathrm{Ti})$ is relatively lower. The second reason is that the size of the formed Laves particles in this work is very small, electron probe microanalysis has a spot size of approximately one micrometer, which is larger than or equal to the particle size, resulting the incorporation of the matrix materials. But under TEM investigation, the

Table 2

EDS analysis results of the particles in Fig. 6 (wt.\%)

\begin{tabular}{|c|c|c|c|c|c|c|c|c|c|c|}
\hline & \multicolumn{10}{|c|}{ Major elements } \\
\hline & $\mathrm{Ni}$ & $\mathrm{Fe}$ & $\mathrm{Cr}$ & Mo & $\mathrm{Al}$ & $\mathrm{Nb}$ & $\mathrm{Ti}$ & $\mathrm{Cu}$ & $\mathrm{Zr}$ & $\mathrm{C}$ \\
\hline Region a & 2.32 & 2.40 & 5.08 & 5.89 & - & 30.47 & 37.51 & 5.71 & - & 10.61 \\
\hline Region b & 46.17 & 36.07 & 10.23 & - & 2.49 & - & - & 5.04 & - & - \\
\hline
\end{tabular}

Table 3

EDS analysis results of the particles in Fig. 7 (wt.\%)

\begin{tabular}{|c|c|c|c|c|c|c|c|c|c|c|}
\hline Major elements & $\mathrm{Ni}$ & $\mathrm{Fe}$ & $\mathrm{Cr}$ & Mo & $\mathrm{Al}$ & $\mathrm{Nb}$ & $\mathrm{Ti}$ & $\mathrm{Cu}$ & $\mathrm{Zr}$ & $\mathrm{C}$ \\
\hline Particles a & 19.15 & 12.82 & 5.59 & 8.44 & 0.70 & 30.37 & 7.02 & 10.27 & 4.64 & 1.00 \\
\hline Particles b & 5.62 & 5.35 & 4.41 & 13.77 & 0.21 & 46.16 & 10.93 & 12.40 & - & 1.16 \\
\hline
\end{tabular}



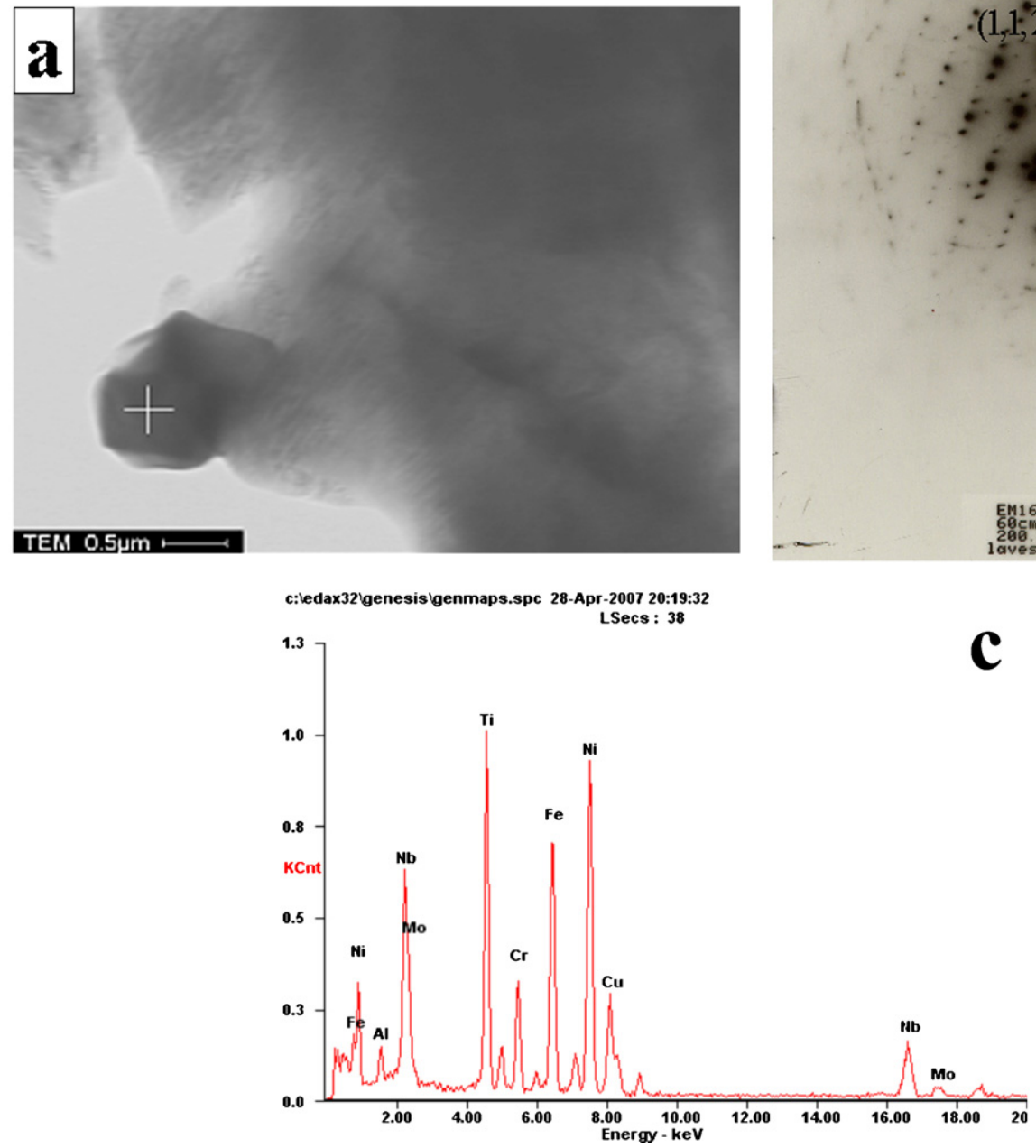

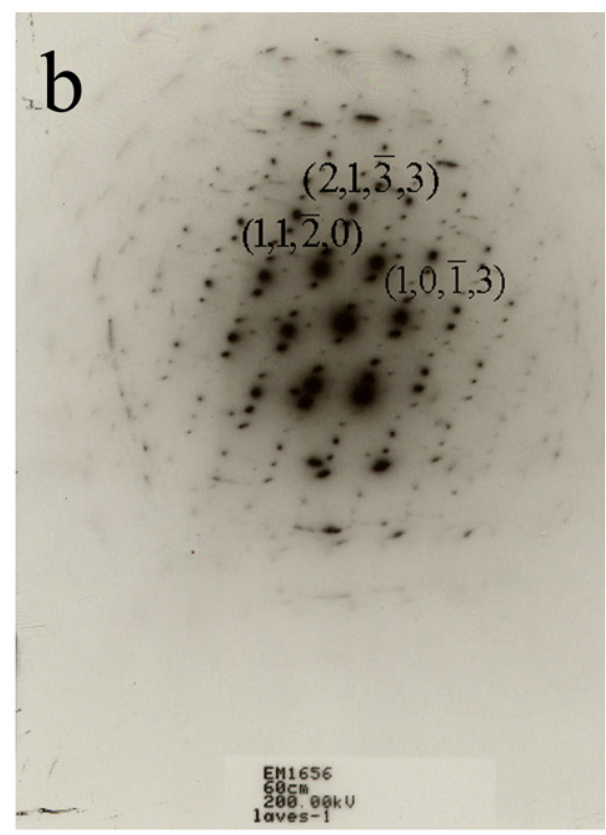

Fig. 5. Laves particles in the welded seam: (a) bright field image, (b) SAED pattern in [3 $\overline{3} 0 \overline{1}]$ zone axis and (c) the corresponding EDS results.

magnification is much higher than SEM, so the electron probe microanalysis is relatively more accurate because the information of matrix materials does not incorporated any more. So it is reasonable to say that under the condition of analyzing the fine and super-fine microstructure, TEM is more powerful than SEM to identify the phase constitutions.

It is worthy to note that two interesting phenomena existed in the welding fusion zone, the first one is variable contrast could be observed in 'a big particle' under TEM and therefore the possibility of the presence of more than one phase in the 'big particle', as indicated in Fig. 6. The corresponding EDS analyses (see Tables 2 and 3) suggest that the region in Fig. 6(a) is $\mathrm{MC}$ type ( $\mathrm{Ti}, \mathrm{Nb}) \mathrm{C}$ carbides and the region in Fig. 6(b) is the $\gamma$-FeCrNiC austenite solid solution matrix. The other phenomenon is some Laves particles are closely related with ( $\mathrm{Ti}$, $\mathrm{Nb}) \mathrm{C}$ carbides besides its isolated distribution, as can be seen in Fig. 7(a) and (b).
As well known, the effects of Laves phase for the resultant mechanical properties depends on its amount and morphology. Strengthening effects generally accompany the fine and dispersive precipitates, while detrimental (decreased ductility) effects for its large amount [18-20]. As in this study, the interface between Laves particles and $(\mathrm{Ti}, \mathrm{Nb}) \mathrm{C}$ carbides could facilitate the initiation and propagation of the microcracks and micro-voids under aggressive external stress, and hence, the detrimental effects of the tensile strength of the welded joint, as evidenced by our previous work [13]. So, the formation of Laves particles, including their morphology, distribution, size and percentage etc warrants careful control. Further studies will be focused on the optimization of laser welding and the post-weld heat treatments to control the Laves particle's quantity and morphology and their effects on the microstructure and mechanical properties of the laser welded joint. 

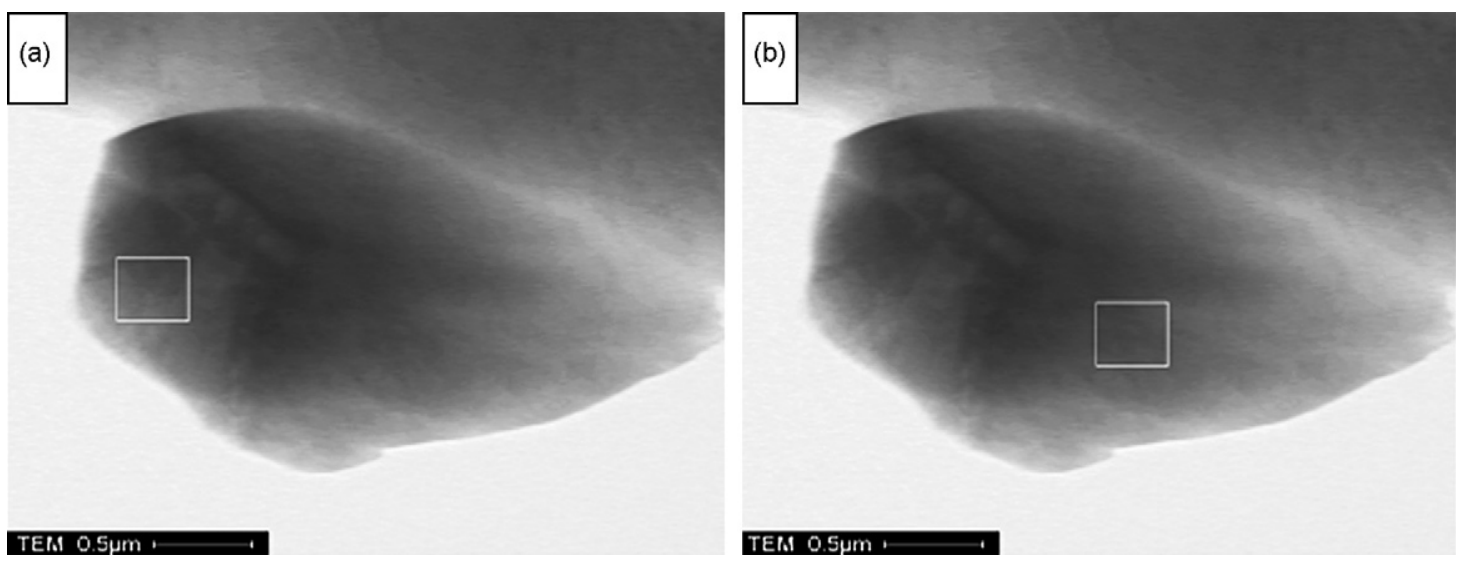

Fig. 6. Variable contrast observed in a 'big particle' under TEM shows the presence of MC carbide and $\gamma$-FeCrNiC matrix in it.
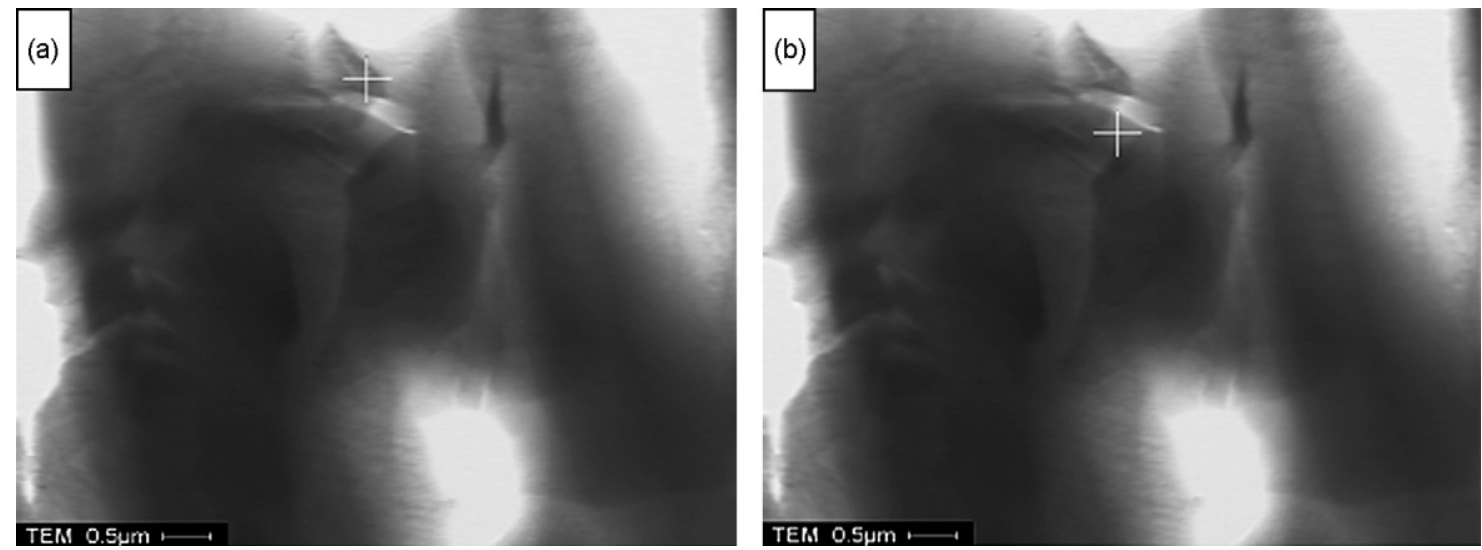

Fig. 7. The close related Laves particles (a) and carbide particle (b)

\section{Conclusions}

Based on the above TEM analyses, it can be concluded that there are mainly $\gamma$ - $\mathrm{FeCrNiC}$ austenite solid solution dendrites as the matrix, (Nb, Ti) $\mathrm{C}$ type $\mathrm{MC}$ carbides, fine and dispersed $\mathrm{Ni}_{3} \mathrm{Al}\left(\gamma^{\prime}\right)$ phase as well as particle-like Laves phase in the welded seam. The existence of these phases is governed by both the kinetic and thermodynamic principles of the non-equilibrium laser welding process.

\section{Acknowledgements}

The research was financially supported by the China Postdoctoral Science Foundation (Grant Number: 20060400105). The authors would like to thank Dr. Hong-Wei Song, senior engineer Wei-Jian Ning, engineer Li-Xin Wang and PhD student HengHai Wang of the Laboratory for Laser Intelligent Manufacturing, Institute of Mechanics, Chinese Academy of Sciences, for their help and suggestions during the laser welding experiments. The authors also wish to thank the reviewers for their constructive suggestions and comments.

\section{References}

[1] S.G. Du, L. Fu, J.W. Wang, Y. Cao, Chin. J. Nonferrous Metals 13 (2) (2003) 323-327 (in Chinese).
[2] G.X. Luo, G.Q. Wu, Z. Huang, Z.J. Ruan, Chin. J. Lasers 34 (2) (2007) 283-287 (in Chinese).

[3] M.L. Zhong, H.Q. Sun, W.J. Liu, X.F. Zhu, J.J. He, Scr. Mater. 53 (2005) $159-164$.

[4] X.F. Yao, H.Y. Yeh, W. Xu, Fatigue Fract. Eng. Mater. 28 (12) (2005) $1191-1198$

[5] Z. Sun, J.C. Ion, J. Mater. Sci. 30 (1995) 4205-4214.

[6] Z. Sun, M. Kuo, J. Mater. Process. Technol. 87 (1999) 213-222.

[7] O.A. Ojo, R.G. Ding, M.C. Chaturvedi, Scr. Mater. 54 (2006) 21312136.

[8] O.A. Ojo, N.L. Richards, M.C. Chaturvedi, Scr. Mater. 51 (2004) 683688.

[9] T.A. Mai, A.C. Spowage, Mater. Sci. Eng. A 374 (2004) 224-233.

[10] A. Ribolla, G.L. Damoulis, G.F. Batalha, J. Mater. Process. Technol. 164-165 (2005) 1120-1127.

[11] T.Y. Kuo, H.C. Lin, Mater. Sci. Eng. A 416 (2006) 281-289.

[12] X.-B. Liu, G. Yu, M. Pang, J.-W. Fan, H.-H. Wang, C.-Y. Zheng, Appl. Surf. Sci. 253 (2007) 7281-7289.

[13] X.-B. Liu, G. Yu, J. Guo, Y.-J. Gu, M. Pang, C.-Y. Zheng, H.-H. Wang, J. Alloys Compd. 453 (2008) 371-378.

[14] X.-B. Liu, M. Pang, Z.-G. Zhang, W.-J. Ning, C.-Y. Zheng, G. Yu, Opt. Lasers Eng. 45 (2007) 929-934.

[15] Y.Y. Qiu, A. Almeida, R. Vilar, J. Mater. Sci. 33 (1998) 2639-2651.

[16] Z. Mei, T.M. Yue, J.K. Yu, J. Mater. Sci. Lett. 21 (2002) 1907-1910.

[17] Z. Mei, W.Y. Wang, A.H. Wang, Mater. Charact. 56 (2006) 185-191.

[18] C. Radhakrishna, K.P. Rao, J. Mater. Sci. 32 (1997) 1977-1984.

[19] G.D. Janaki Ram, A. Venugopal Reddy, K. Prasad Rao, G. Madhusudhan Reddy, Sci. Technol. Weld. Joi. 9 (5) (2004) 390-398.

[20] G.D. Janaki Ram, A. Venugopal Reddy, K. Prasad Rao, G.M. Reddy, J.K. Sarin Sundar, J. Mater. Process. Technol. 167 (2005) 73-82. 